\title{
ESPR EUROPEAN SOCIETY FOR PEDIATRIC RESEARCH
}

\author{
Siena, Italy \\ August 31, 2005 - September 3, 2005
}

\section{1}

PAIN MANAGEMENT: PROSPECTIVE STUDY IN POSTOPERATIVE ABDOMINAL SURGERY IN CHILDREN

C ABADESSO ${ }^{l}, S$ NUNES ${ }^{l}, H$ ALMEIDA ${ }^{l}, R$ CARNEIRO ${ }^{l}$, P CASELLA $A^{l}, J$ FERNANDES ${ }^{l}, M$ OLIVEIRA ${ }^{l}, M C$ MACHADO ${ }^{l}{ }^{\prime}$ HOSPITAL FERNANDO FONSECA (PORTUGAL)

Introduction: Pain in the postoperative period is a rising concern in paediatrics. Ideal management should be the most effective with minimal adverse effects.

Objective: Compare two regimens of analgesia, intravenous morphine, continuous infusion versus intermittent bolus in postoperative children (appendectomy)

Methods: Randomised, triple-blinded, placebo controlled study in children aged 1 month to 14 years (November 2001 to December 2003). Children were randomised in two groups: (A) morphine continuous perfusion $(0,02 \mathrm{mg} / \mathrm{Kg} / \mathrm{h})$; (B) normal saline continuous perfusion. Both groups received bolus of morphine $(0,03 \mathrm{mg} / \mathrm{Kg})$, according to pain scale. Demographic data; duration of symptoms; surgical appendicitis staging; duration of perfusion, number of boluses; pain measurement (Faces Rating Scale), every 4 hours (first 48 hours); time until enteric feeding, first stool emission; complications and duration of hospitalization were analysed.

Results: Included 102 children $(A=52 ; B=50$ ). Groups were identical in age (mean years: $A=9,7$; $B=10,1$ ), sex , duration of symptoms before surgery (mean hours: $A=40,2, B=31,8$ ), surgical appendicitis staging. There was no statistical significant difference in: duration of perfusion (mean hours: $A=26,4, B=25,8 ; p=0,8$ ), number of boluses (mean: $A=1,27, B=2,0 ; p=0,09$ ), and pain rating. In group B, children with peritonitis showed more pain in the first $24 \mathrm{~h}$ and needed more boluses (mean: $\mathrm{A}=0,6, \mathrm{~B}=3,7 ; \mathrm{p}<0,05$ ). There were no differences in: beginning of enteric feeding, (mean (mean: $A=0,6, B=3,7 ; p<0,05)$. There were no differences in: beginning of enteric feeding, (mean
$\mathrm{A}=21 \mathrm{~h}, \mathrm{~B}=23 \mathrm{~h} ; \mathrm{p}=0,38)$, first stool emission (mean days: $\mathrm{A}=2,69, \mathrm{~B}=2,33 ; \mathrm{p}=0,14)$; respiratory complications $(\mathrm{A}=0, \mathrm{~B}=0)$, vomiting $(\mathrm{A}=11, \mathrm{~B}=9 ; \mathrm{p}=0,8)$, urinary retention $(\mathrm{A}=1, \mathrm{~B}=3 ; \mathrm{p}=0,35)$ and duration of hospitalisation (mean days: $A=3,74, B=3,78 ; p=0,9$ ).

Conclusion: Both analgesia regimens were equally effective in the less severe appendicitis stage, without major adverse effects. In patients with peritonitis, morphine perfusion was significantly more effective in pain control.

\section{3}

DEVELOPMENTAL CONTRACTILE RESPONSE IN THE CHICKEN EMBRYO DUCTUS ARTERIOSUS IN VITRO

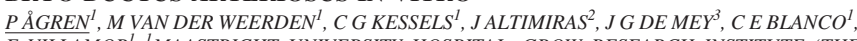
E VILLAMOR ${ }^{1}$ MAASTRICHT UNIVERSITY HOSPITAL, GROW RESEARCH INSTITUTE (THE NETHERLANDS), ${ }^{2}$ UNIVERSITY OF LINKÖPING, IFM, BIOLOGY (SWEDEN), ${ }^{3}$ PHARMACOLOGY UNIVERSITY OF MAASTRICHT (THE NETHERLANDS)

Background and aim: During prenatal life the chicken embryo presents a pattern of circulation similar to mammalians. Despite the abundant information about ontogeny of vascular reactivity in mammalian ductus arteriosus (DA), this has not been characterized in the chicken embryo. The aim of the present work was to study the response to vasoconstrictors of the chicken embryo DA between 0.7 and 0.9 incubation.

Methods: Isolated right DA segments from chick embryos at day 15 and day 19 of the 21-d incubation were mounted in a myograph for isometric tension recording, bubbled with $0 \%, 5 \%$ or $95 \%$ O2/5\% CO2. The contractile responses induced by $\mathrm{KCl}(31.25 \mathrm{mM}-125 \mathrm{mM})$, the thromboxane $\mathrm{A} 2$ mimetic U46619 (10 nM- 0.1 microM), endothelin-1 (ET-1, $10 \mathrm{nM}-10$ microM), and the adrenergic agonist noradrenaline (NA, $0.3 \mathrm{nM}-10 \mathrm{mM}$ ) were tested. Response to oxygen was tested in a separate protocol. Sympathetic neuroeffector mechanisms were studied using electrical field stimulation (EFS $0.2516 \mathrm{~Hz}, 2 \mathrm{~ms}, 85 \mathrm{~mA})$. Density of sympathetic innervation was evaluated using glyoxylic acid staining.

Results: Chicken embryo DA responded to depolarizing high-K+ solution with a tonic contraction that increased with age. Also the contractile responses to NA, U46619 and ET-1 augmented. Depletion of calcium abolished the contractile response to $\mathrm{K}+$ and NA, whereas the response to ET- 1 decreased $77 \%$ and to U46619 decreased 20\%. EFS did not evoke any response and catecholamine-containing perivascular nerves were not observed at any age. No clear response to oxygen in either 15 or 19 days embryos was observed. A contractile response to oxygen was only observed in 21 days externally pipped embryos.

Conclusions: The DA of the chicken embryo responded, in vitro, to receptor-dependent and -independent contraction. The responses to contractile agonists augmented with age. The response to oxygen was only present at a very late stage of incubation.
LONG TERM SENSITISATION OF MECHANICAL SOMATOSENSORY WITHDRAWAL RESPONSES FOLLOWING PRETERM BIRTH

HMABDULKADER ${ }^{l}$, S FLEETWOOD-WALKER ${ }^{2}$, NMCINTOSH $^{l}{ }^{\text {NNEONATOLOGY, UNIVERSITY }}$ OF EDINBURGH, ${ }^{2}$ VETRINARY MEDICINE, UNIVERSITY OF EDINBURGH (UK)

Background: Critically ill preterm (PT) infants are exposed to a large number of invasive procedures especially in the first week after birth. There is anxiety that such exposure migh permanently affect their vulnerable nervous system. The flexion withdrawal reflex (FWR) from mechanical (Von Frey hair; VFH) stimulation can be used as a test of the threshold for aversive withdrawal responses, but does not cause distress.

Aim: To investigate whether ex-preterm infants $(<=34$ weeks gestation) are more sensitive to VFH stimulation during the first year of life, than infants born full term. Subjects and Methods: The thresholds for the FWR and gross body movements (GBM) response to peripheral (heel) stimulation with VFH were studied in 63 full term infants and 62 ex-preterm infants during their first year of life. The thresholds were taken as a measure of somatosensory sensitivity. Response threshold were compared by unpaired $t$ tests.

Results: At corrected term age the threshold for both the FWR and the GBM responses were significantly lower in $\mathrm{PT}$ infants ( $<<0.001, \mathrm{p}<0.001$ respectively). During the first year the thresholds for the preterm infants remained significantly and markedly more sensitive $(\mathrm{p}<0.001)$. The threshold for FT infants steadily increases during the first year but the threshold for the PT infants remains the same magnifying the difference in the 2 groups. The threshold for GBM responses in both FT and PT infants increase during the year but there is always a marked and significant difference $(\mathrm{p}<0.012)$.

Conclusion: Either PT birth or repetitive procedures associated with such PT birth alters the sensitivity threshold of PT infants compared with FT infants and this increased sensitivity remains for at least the first year of life.

\section{4}

RESPONSE OF CHICKEN EMBRYO DUCTUS ARTERIOSUS TO NO/CYCLIC GMP- AND CYCLIC AMP-MEDIATED RELAXATION

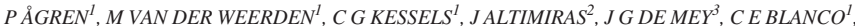
EVILLAMOR I IPEDIATRICS, MAASTRICHT UNIVERSITY HOSPITAL, GROW RESEARCH INSTITUTE (THE NETHERLANDS), ${ }^{2}$ UNIVERSITY OF LINKÖPING, IFM, BIOLOGY (SWEDEN), ${ }^{3}$ PHARMACOLOGY UNIVERSITY OF MAASTRICHT (THE NETHERLANDS)

Background and aim: The mammalian ductus arteriosus undergoes alterations in its pharmacological responsiveness with advancing gestational age. Cyclic AMP and cyclic GMP are second messengers involved in the regulation of ductus arteriosus tone. The aim of the present work was to study the ontogeny of cAMP- and cGMP-evoked ductus arteriosus relaxation in the chicken embryo between 0.7 and 0.9 incubation.

Methods: Isolated right ductus arteriosus segments from chicken embryos at day 15 and day 19 of the 21-d incubation were mounted in a myograph for isometric tension recording, bubbled with $0 \%$, $5 \%$ or $95 \% \mathrm{O} 2 / 5 \% \mathrm{CO} 2$. Relaxations induced by acetylcholine $(\mathrm{ACh}, 0.1 \mathrm{nM}-10 \mathrm{mM})$, the nitric oxide (NO) donor, sodium nitroprusside (SNP, $0.1 \mathrm{nM}-30 \mathrm{mM}$ ), the adenylate cyclase activator, forskolin (10 microM- 0.3 microM) and the beta-adrenergic agonist, isoproterenol $(0.1 \mathrm{nM}-10 \mathrm{mM})$, were evaluated during contraction induced by $62,5 \mathrm{mM} \mathrm{K}+$. Some experiments were performed in the presence the NO synthase inhibitor L-NAME $(0.3 \mathrm{mM})$, the soluble guanylate cyclase inhibitor ODQ, ( 0.1 microM) or the beta-blocker propanolol $(0.1$ microM).

Results: Relaxations induced by ACh (inhibited by L-NAME and ODQ), SNP (inhibited by ODQ), forskolin, and isoproterenol (inhibited by propanolol) were not significantly different between 15 and 19 days. Forskolin and isoproterenol completely reversed $\mathrm{K}+$-induced contraction, whereas ACh and SNP only caused respectively $40 \%$ and $60 \%$ maximal relaxation. Bubbling the organ chamber with $95 \% \mathrm{O} 2$ instead of $5 \% \mathrm{O} 2$, reduced the response to ACh and SNP in both groups of age.

Conclusions: The ductus arteriosus of the chicken embryo responded, in vitro, to NO/cGMP- and cAMP-mediated relaxation, without significant developmental changes. cAMP mediated relaxation was more potent than NO/cGMP mediated relaxation. Oxygen tension modulates chicken embryo ductus arteriosus relaxation. 